\title{
Optimal Hybrid Filtering Strategy Using Adaptive Genetic- Fuzzy Logic Control for Harmonics Reduction in a Standalone Micro Hydroelectric Power Plant Coordinated with a PV System
}

\author{
Adel Elgammal and Curtis Boodoo
}

\begin{abstract}
Micro Hydro Power Plants are a type of power production that uses the force of river flows or waterfalls to generate electricity. The generator generates current waves and harmonic voltage, which are distorted wave disturbances that cause fundamental frequency multiplication. The major goal of this work is to design a reliable, efficient, and innovative harmonic mitigation approach for a stand-alone micro hydroelectric system that is coordinated with a photovoltaic renewable energy system utilising an active power filter. We may pick the active filter highest harmonic to be suppressed using the magnitude information supplied for each harmonic component. A hybrid filtering approach to remove harmonics and a novel MOGA optimization technique are part of the suggested harmonics reduction solution. The goal of this article is to determine the optimum filter for decreasing harmonics in an induction generator. As the harmonic damper, two filters were chosen: a passive filter and an active power filter. The suggested MOGA control method is compared to GA and evaluated on simulated data. In tracking harmonic components and fundamental frequency, the suggested MOGA control system provides high convergence speed and accuracy. It's extremely adaptable, and it can predict changes in the phase angle, amplitude, and fundamental frequency of harmonic components. When compared to the Genetic Algorithm method, it performs better. Simulation results using the SIMULINK/MATLAB simulation tool are delivered to evaluate the efficacy of the suggested active filter system. The impact of harmonic currents on the magnetic flux density is investigated using the rated condition as a reference. It has been established that the time harmonic is a significant element influencing generator performance. At the same time, the impacts of harmonic currents on the generator's eddy current loss, average torque, and torque ripple are investigated, as well as the mechanism of eddy current loss fluctuation.
\end{abstract}

Index Terms - Active Filter, Harmonics Reduction, Micro Hydropower Plant, Passive Filter, Synchronous Generator, Total Harmonic Distortion.

\section{INTRODUCTION}

Developing technology and growing population are increasing the need of countries for energy every passing day. Renewable energy resources, which are an environmentally friendly and local solution alternative to fossil fuels, are seen to be a significant source of supply in this matter [1]. Among renewable energy resources,

Submitted on July 19, 2021.

Published on August 09, 2021.

Adel Elgammal, The University of Trinidad and Tobago UTT, Utilities Engineering, Point Lisas Campus, Trinidad and Tobago. (corresponding e-mail: adel.elgammal @utt.edu.tt)

Curtis Boodoo, The University of Trinidad and Tobago UTT, Utilities Engineering, Point Lisas Campus, Trinidad and Tobago.

(e-mail: curtis.boodoo@utt.edu.tt) hydroelectric energy is in an advantageous position with its reliable potential and sustainable production. With the purpose of utilizing small flowing waters such as rivers and streams and solving problems of access to interconnected grids in rural areas, micro-type hydroelectric power plants have a significant potential for countries [2]. Due to their low cost and poor system performance, micro-hydroelectric systems are often employed in distant rural regions. This generator generates harmonic waves, which are distorted wave disturbances that cause fundamental frequency multiplication [3]. Because of the widespread usage of power electronic load, AC distribution networks have recently faced severe harmonic pollution. These non-linear loads cause harmonies, which cause distribution systems to deteriorate and can impair control systems and communication [4]. Harmonic filters are meant to decrease the effects of harmonic penetration in power systems and should be fitted when the acceptable harmonic content has been surpassed. To decrease the influence of harmonic distortion, two techniques have been proposed, namely active filtering and passive filtering [5]. The disadvantages of passive filters are their fixed compensation, resonance, and large size. The harmonic currents created by nonlinear loads are removed in the active filtering technique, and their inverses are generated and introduced into power line by means of power converter [6]. Several active filtering techniques have been presented, each based on a different control theory and circuit topology. The majority of these active filter systems are made up of a single high-capacity PWM power converter that filters out all of the distorted signal's harmonic components [7]. Excessive power losses occur from the combination of high switching frequency and high power. Furthermore, the current active filters' reliability is a major issue, since if the converter fails, there is no compensation. Filtering active power lines can be done in frequency domain or in time domain. As the information on each harmonic component is readily available, frequency-domain methods have the particular benefit of allowing selective harmonic removal [8]. Different topologies of shunt active power filters have been demonstrated in literature to be successful in a number of applications using a variety of control techniques, including direct power control [10], instantaneous reactive and active power control [9]. This method has a number of advantages, including robustness and ease of control [11]. All of these approaches, of course, are designed to adjust for reactive power while simultaneously reducing distortions and harmonics. The inverter is used in two ways in this study: first, it injects active power into the grid, and second, it compensates line current harmonics, lowering the cost of a shunt active power filter [12]. 
Different metaheuristic optimization approaches, such as Proportional, Integral, and Derivative and Proportional and Integral are often employed in tuning of conventional controllers and are given in the literature [13]-[15]. Because no standard way for effectively tuning the gains of a PI controller has been discovered, optimal gains are difficult to achieve using traditional approaches [16]. Many evolutionary algorithm-based optimization approaches, such as bacterial foraging [21], artificial bee colony [20], ant colony optimization (ACO) [19], PSO [18], and genetic algorithm [17] have been effectively utilized in variety of everyday industrial optimization issues. [22] Uses firefly optimization to study the layout of a SAPF as an optimization problem, with the main goal of reducing total harmonic distortion. The Bat algorithm is based on pqtheory and was developed in [23] to enhance the direct current connected voltage regulator and minimize current harmonics generated by non-linear load. To enhance the system functioning for a Shunt Active Power Filter, Proportional and Integral controller gains are adjusted by means of Particle swarm optimization and enhanced PSO in [24]. The GWO is used in [25] to enhance wind turbine induction generator power flow compensation by adjusting and attaining optimal values for a Proportional and Integral controller. [26] Uses a hybrid PSO-GWO to optimize a fractional order Proportional, PI controller for a hybrid SAPF. To achieve the best performance of the direct current linked voltage, steady state error, settling time, overshoot and rising time are included into the fitness function under several operating circumstances. [27] Presents enhanced dynamic functioning of SAPF utilizing PSO to adjust a standard Proportional and Integral controller based on updated pq theory and DC-link voltage. DC-link Overshoot, settling time, and voltage ripples are all essential objectives in this study. When compared to traditional PI, simulation findings demonstrate that PI-PSO provides a significant improvement. [28] Describes a three-phase SAPF that uses DPC based on PSO to improve power quality. The gains of the proportional and integral controllers of the direct current connected voltage loop are tuned using particle swarm optimization in this work. The collected findings demonstrate that proportional and integral -based particle swarm optimization provides better outcomes in terms of undershoot reduction, DC-link response overshoot, harmonic minimization, and robustness. [29] Proposes an enhanced artificial bee colony algorithm, a hybrid optimization technique for achieving optimal gains of proportional and integral controllers in order to improve single phase SAPF dynamic performance. The integral square error is minimized using an objective function. The obtained findings demonstrate improved functioning in terms of settling time, source current THD and maximum direct current linked voltage overshoot. [30] Describes the use of Ant Colony Optimization to fine-tune the proportional and integral controller gains in order to increase the performance of SAPF control connected to the integral square error objective function. Genetic algorithm is used in [31] to tune the settings of Proportional and Integral controllers as well as the values of the SAPF's inductor and capacitor to improve performance. The proposed technique is shown in this paper using the
Simulink environment, and outcomes indicate an improvement in THD.

The suggested active filter is given a novel control method in this work to monitor the system voltage and extract the major constituent of source voltage, which is utilized as a synchronize signal for DC current regulation loop. The suggested modular active filter's filtering capability is improved as a result. The controller changes the converter modules' direct current side current centered on the magnitude of harmonics to be filtered. As a result, the dc-side current value is optimized, and converter losses are minimized. As a consequence, efficiency and performance will improve. The suggested active power system tackles the low-order harmonics individually, rather than attempting to provide active filtering for the whole spectrum of harmonic components. For the goal of improving power quality, several active power filtering techniques and concepts have been proposed.

\section{VARIABLE SPEED HYDROELECTRIC POWER GENERATION SYSTEM CONFIGURATION}

Micro hydro systems with variable speeds allow for more precise control of output frequency and voltage, as well as the application of maximum efficiency tracking and maximum power point approaches. One of the approaches utilized is permanent magnet synchronous generators with double conversion inverters. The direct drive is advantageous for the following reasons: Variable speed micro hydro systems frequently employ permanent magnet synchronous generators with back-to-back converters. Because the converter decouples the generator from the grid, grid disruptions have lower impact. Because of their great power density and efficiency, permanent magnet synchronous generators offer exceptional electric driving capabilities. The speed control range of permanent magnet synchronous generators with full power converters is greater than that of other PMSGs, and the PMSG setup is simpler and hence less expensive. The usage of a double conversion inverter allows for variable speed operation. In principle, a simple servomechanism that allows the output frequency to alter regulates the turbine's speed within working limits. The generator's output is transformed to DC via an inverter, which is then converted to alternating current at the proper frequency and voltage. The inverter, not the turbine rotational speed, is in charge of frequency stability. A two-way converter The PSMG micro hydro system is made up of three major components. A grid side output converter transforms direct current to alternating current at the required frequency and voltage, a direct current link controls the output voltage, and a generator side rectifier/conversion converts the generator's output to direct current. The twofold conversion method may be set up in two different ways. If the direct current voltage is generated by an uncontrolled rectifier and the alternating current voltage is generated by a controlled converter. The direct current voltage will fluctuate as the output of the permanent magnet synchronous generators varies with speed. The direct current Link compensates for this by incorporating a boost/buck converter. The direct current voltage is generated using a regulated converter. This allows the direct 
current voltage to be changed by altering the switching pattern of the converter. Control loops can be added to the system to control the turbine's functioning. Micro hydro output power may be increased by using MPPT or MEPT. Synchronous speed is rarely the optimal speed for extracting energy from a water source. If the turbine's rotational speed is raised while the torque input remains constant, the turbine's output power will rise. The link between the rotation speed and output voltage frequency must be decoupled to adjust output power from turbine and generator, which may be performed by means of double conversion system. Variable-speed operation is essential to guarantee optimal efficiency in the micro hydro power generating system because efficiency of hydraulic turbine is sensitive to rotational speed changes and water flow rates. Power production and Efficiency hence, changes with rotation speed for a constant flow rate. The rotation speed at the maximum efficiency point is affected by variations in water flow rates. Maximum power point tracking's main objective is to keep the turbine shaft rotating at a rate that generates the highest efficiency or power for a given flow rate. The dynamic equilibrium between the PMSG's electromagnetic torque and the input hydraulic driven torque determines the rotation speed. The electromagnetic torque is proportional to the current in the output circuit of the converter. The generator side converter controls the current flowing while the grid side converter regulates the frequency in a maximum power point tracking system. On a Pulse-width modulation converter-based structure, the generator side current is regulated by the Pulse-width modulation driver under the control of the MPPT system. The boost converter, which is powered through the MPPT system, regulates the current flowing in the rectifier-based system, as illustrated in Fig. 1. The active filter power converter is rated according to the quantity of injected current and is switched at the frequency required to complete the filtering function. The suggested active filter system is made up of a series of parallel single phase modules, each of which is devoted to suppressing a distinct low-order harmonic. When the order of the harmonic to be filtered is raised, the power rating of the modules decreases, but the switching frequency of the modules increases. Consequently, total switching losses are decreased significantly. Because the power converter units in the proposed active power filter are self-contained, partial harmonic distortion correction is possible even if one (or more) power converters fail. Even so, the line current spectrum will be better than in the uncompensated scenario. Due to the independent connection of the filter modules to the AC system and the ability of selective harmonic removal based on the dominant harmonic component, the proposed filter system displays improved overall performance and significant flexibility. Using the diversity concept, the proposed filter system may filter a set of harmonies using one or more filter modules, compensating, and combining them in groups. Other disturbances, for example voltage variations and current or voltage imbalance can also be addressed using simultaneous multi-operation methods. The active power-line filter's control approach is critical for improving its effectiveness in suppressing voltage waveforms and harmonic current. As illustrated in Fig. 2, active power line filtering can be done in the frequency domain or the time domain. The converter is forced to inject the correct compensatory current by the control system, which processes the distorted line voltage and current data. At the same time, it controls the converter's dc-side voltage or current. The precision and speed of the power Line harmonic current detection tool has a major influence on the frequency domain functioning of active power filters. The generation of a synchronizing signal that is in phase with the bus voltage and is used to manage the direct current side voltage or current of a power converter. This is another important factor that influences active filter management.

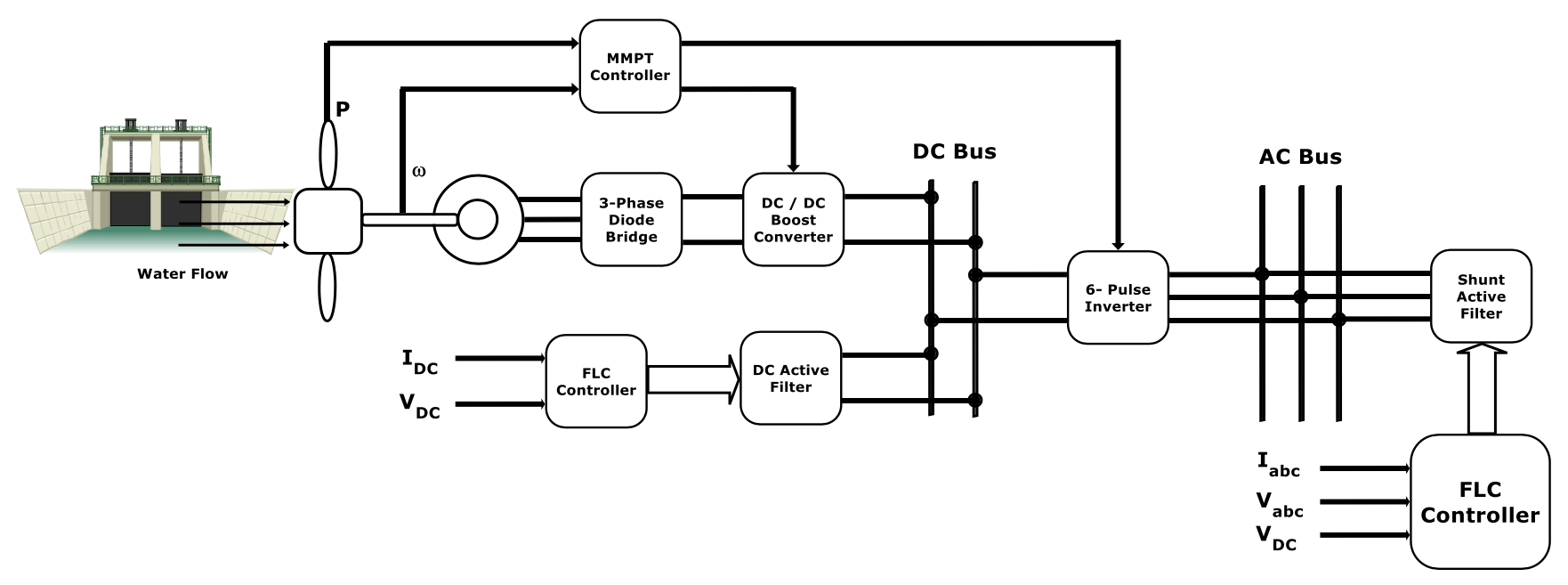

Fig. 1. Variable Speed Hydroelectric Power Generation System Configuration. 


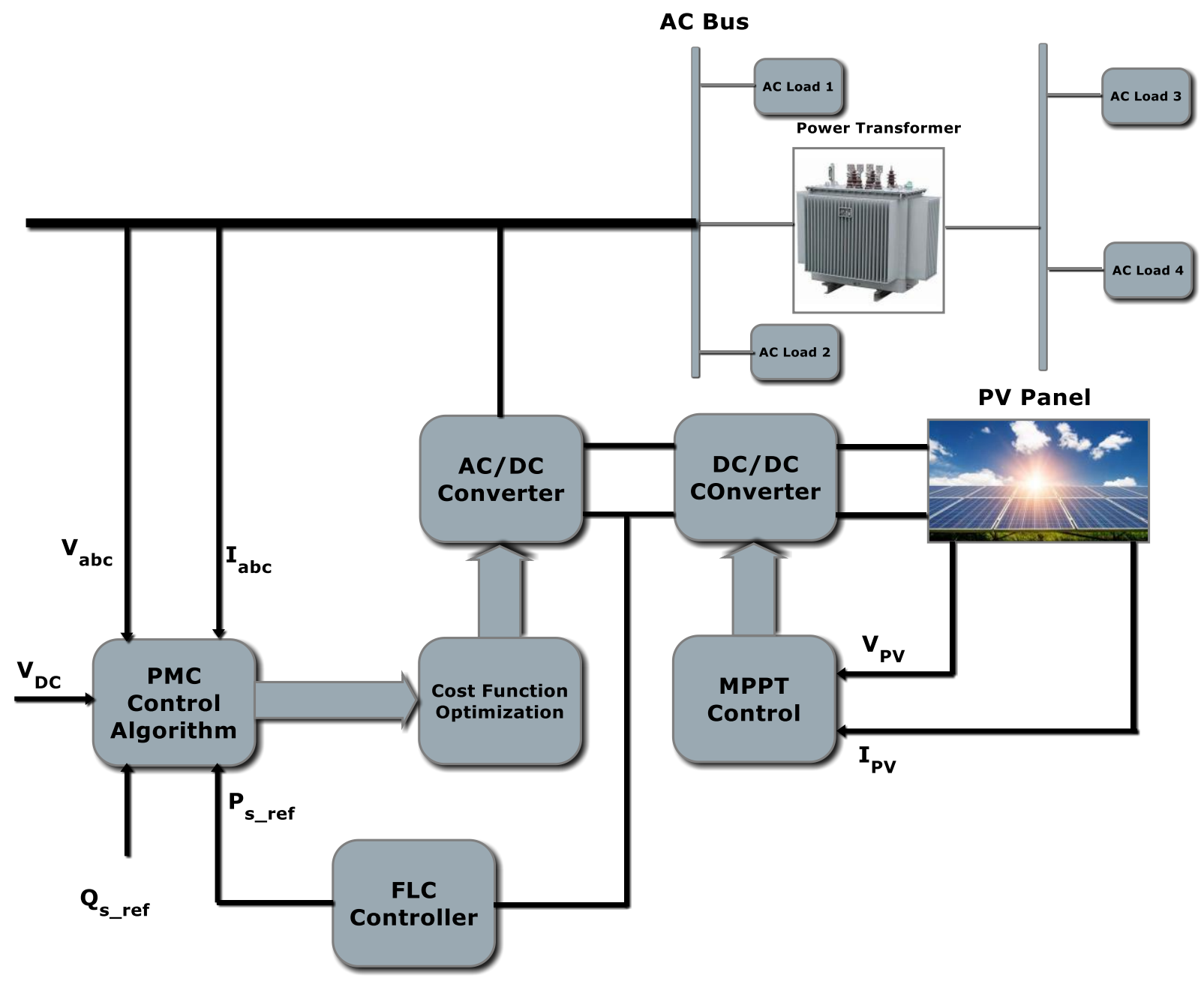

Fig. 2. Configuration of Shunt Active Filter with Direct Power Control.

\section{Simulation Results AND Discussions}

The suggested Adaptive Genetic-Fuzzy Logic Control scheme, which includes the SAPF linked with the solar system, is simulated using Simulink/MATLAB under various climatic circumstances, and the results are compared. Before and after filtering, as well as for active power injection into the main supply from the photovoltaic source via the shunt active power filter, different tests were carried out. A nonlinear load is adjusted by reducing the load by approximately $40 \%$ and then raising the load by about $40 \%$ to demonstrate the performance of a PID Fuzzy logic controller based on optimum gains derived via MOGA. In this article, the two optimization methods SOGA and MOGA are utilised to tune the PI controller settings offline $(\mathrm{Ki}, \mathrm{Kp}$ and $\mathrm{Kd})$. Furthermore, the operating duration of each technique is determined by the features of the PC's CPU as well as the problem under consideration. The goal of this study is to reduce maximal DC-link voltage undershoot and overshoot while keeping THD low and power ripples low. The optimal PID gains may be determined by solving the following equation:

Minimize F:

$$
F=\omega_{1} f_{1}+\omega_{2} f_{2}+\omega_{3} f_{3}+\omega_{4} f_{4}
$$

where, f1 is determined by index Integral Time Square
Error. This reduces the DC-link voltage error area in both steady and transient state. It may be summed up as follows:

$$
f_{1}=\int_{0}^{t} t \cdot\left(V_{d c}^{*}-V_{d c}\right)^{2} d t
$$

The overshoot of DC-link voltage is represented by $f_{2}$. It's possible to provide it as:

$$
f_{2}=\frac{V_{D C_{-} M a x}-V_{D C_{-} s s}}{V_{D C_{-} s s}} \times 100
$$

where VDC max is maximum value and VDC ss is steadystate final value.

The THD of AC current $f_{3}$, which enhance the current's power quality, may be expressed as:

$$
f_{3}=\frac{\sqrt{\sum_{n=2}^{\infty} I_{n}^{2}}}{I_{f}} \times 100
$$

where, $I_{f}$ is RMS value of fundamental AC current. While $I_{n}$ is the source current's RMS value for the nth harmonic.

The THD of an AC voltage $f_{4}$, which improves its power quality, may be expressed as: 


$$
f_{4}=\frac{\sqrt{\sum_{n=2}^{\infty} V_{n}^{2}}}{V_{f}} \times 100
$$

where $V_{f}$ : the RMS value of the fundamental AC voltage, $V_{n}$ : the source voltage's Root Mean Square (RMS) value for the nth harmonic.

All effects are given a weighted factor of $\omega_{1}, \omega_{2}, \omega_{3}$ and $\omega_{4}$. The absolute values of these weights are added together and reported as:

$$
\omega_{1}+\omega_{2}+\omega_{3}+\omega_{4}=1
$$

According to numerous studies, the increase in weighting factor for f1 "ITSE" causes significant undershoot and overshoot. Increased weighting factor for f3 “THD” causes excessive undershoot and overshoot, as well as significant steady state inaccuracy. In this experiment, $\omega_{1}$ is set to 0.1 , $\omega_{2}$ to 0.5 , while $\omega_{3}$ and $\omega_{4}$ are both set to 0.2 . The convergence performance reflecting the optimum value of the fitness function of SOGA approach is compared with MOGA based on numerical results of the test utilizing optimal gains achieved by SOGA and MOGA for the PID gains ( $\mathrm{Ki}, \mathrm{Kp}$, and $\mathrm{Kd}$ ). To achieve the final result, the MOGA needs around 25 iterations with a running duration of 28.7 seconds. The SOGA, on the other hand, takes 67 iterations and 56.8 seconds to complete. Moreover, MOGA's fitness function has a lower fitness value than SOGA's. Figures 3-6 show simulation results for source current and injected current, active, and reactive powers, DC-link voltage, and spectrum of source current harmonics for the conventional method. It also shows the best values obtained by SOGA and MOGA under load variation for the conventional method and the best values obtained by SOGA and MOGA. Fig. 3-6 show the results of simulation tests on the standard FLC-PID model and comparisons with the suggested techniques for a variety of performance indices, including THD, power ripples, after SAPF switch-on, startup`s peak active power, undershoot, overshoot, and reaction time. When compared to the conventional approach, simulation of direct current linked voltage response using the 2 suggested approaches, FLC-PID -MOGA and FLCPID -SOGA. It also tracks the target reference value $160 \mathrm{~V}$ extremely rapidly and without any overshoot at start-up. When compared to the standard FLC-PID controller and FLC-PID -SOGA, FLC-PID -MOGA has a lower undershoot $(1.150 \%)$ and overshoot $(1.025 \%)$ and quicker response time $(0.036 \mathrm{sec})$. FLC-PID -SOGA, on the other hand, has the highest THD (2.985 percent), the highest power ripples $(13.536 \%)$, and highest peak active power at startup (1736 W). Furthermore, the FLC-PID -MOGA simulation results show that the recommended FLC-PID MOGA has a higher performance in terms of power ripples $(2.9934 \%)$ and active power peak $(1452 \mathrm{~W})$. In addition, the suggested FLC-PID -MOGA reduces Total harmonic distortion of source current from $27.6 \%$ to $2.3 \%$. It is the lowest value (less than $5 \%$ according to IEEE Standard Std. 519-2014) compared to Total harmonic distortion $=1.7 \%$ for PI and THD $=2.815 \%$ for traditional FLC-PID under load fluctuation. Except for a small increase in undershoot and overshoot, the source current's performance is enhanced.

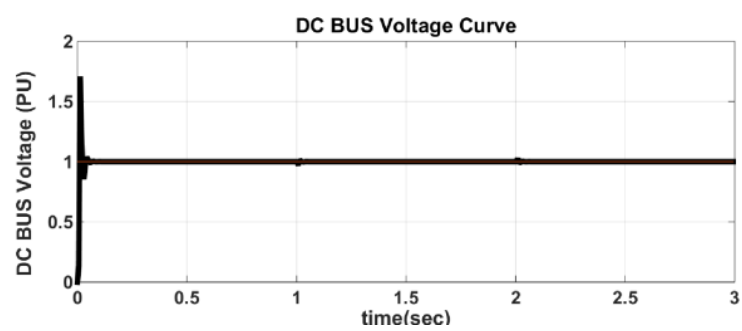

(a)

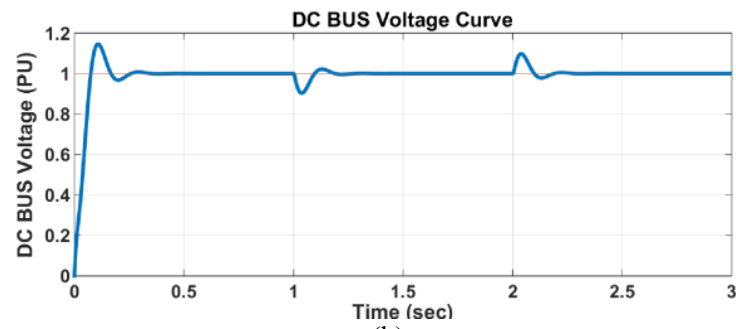

(b)

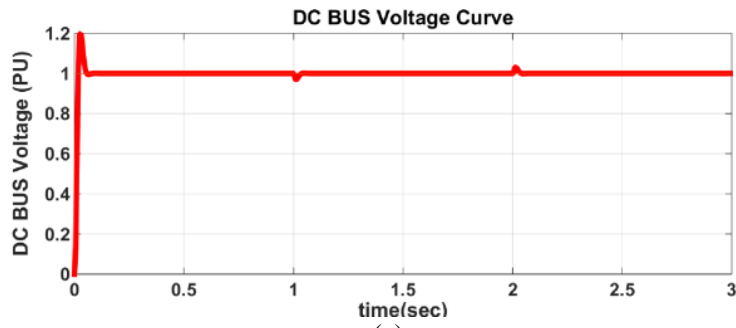

(c)

Fig. 3. Direct current link voltage simulation results with load fluctuation: (a) FLC-PID, (b) FLC-PID -SOGA and (c) FLC-PID -MOGA.

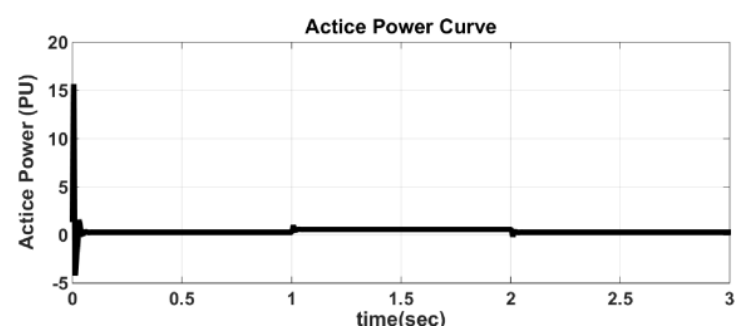

(a)

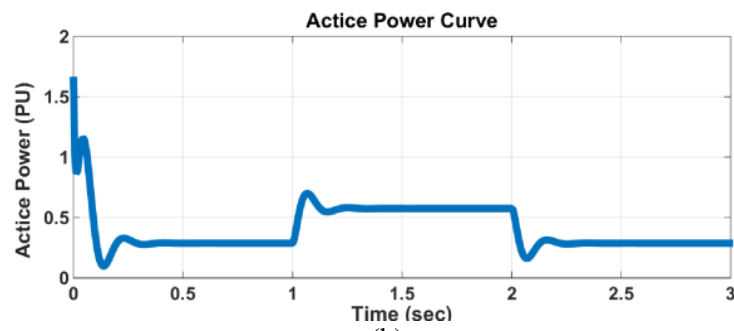

(b)

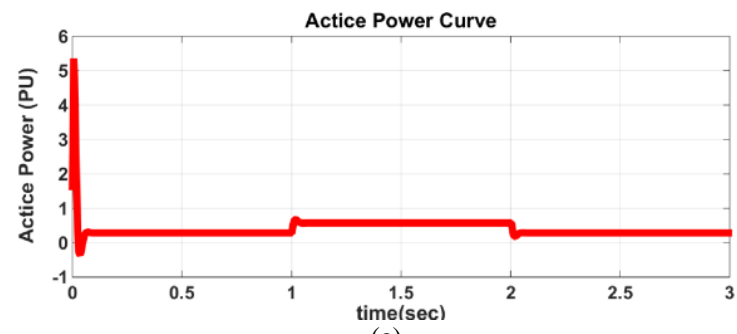

(c)

Fig. 4. Simulation findings of active power as a function of load: (a) FLCPID, (b) FLC-PID -SOGA and (c) FLC-PID -MOGA 


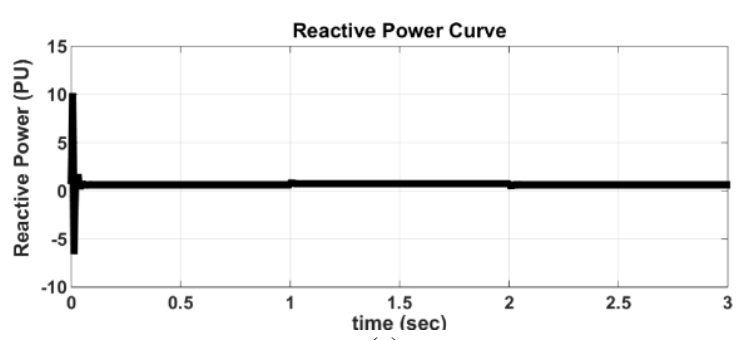

(a)

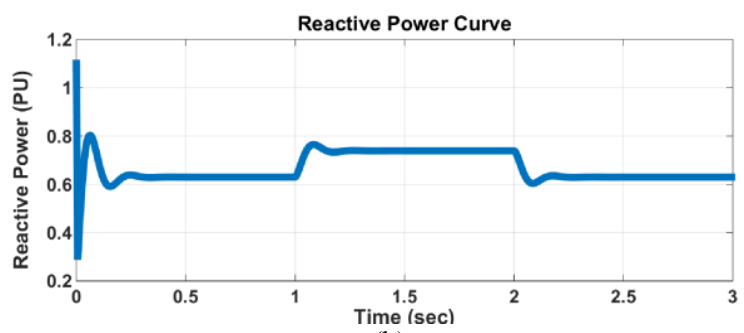

(b)

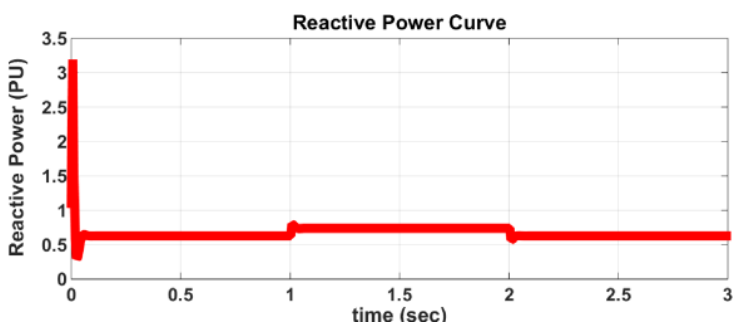

(c)

Fig. 5. Reactive power simulation results with load variation: (a) FLC-PID, (b) FLC-PID -SOGA and (c) FLC-PID -MOGA.

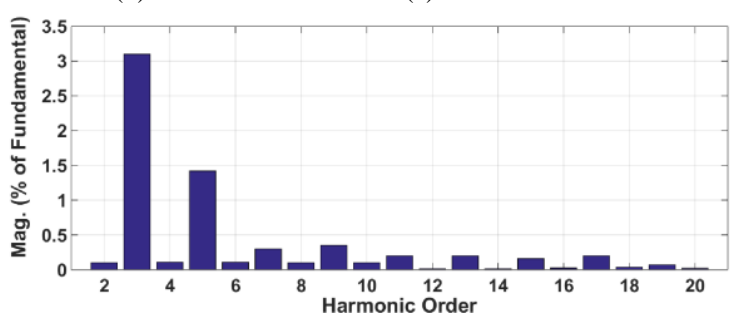

(a)

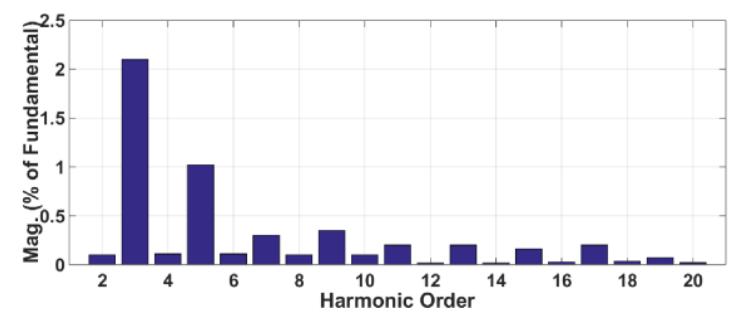

(b)

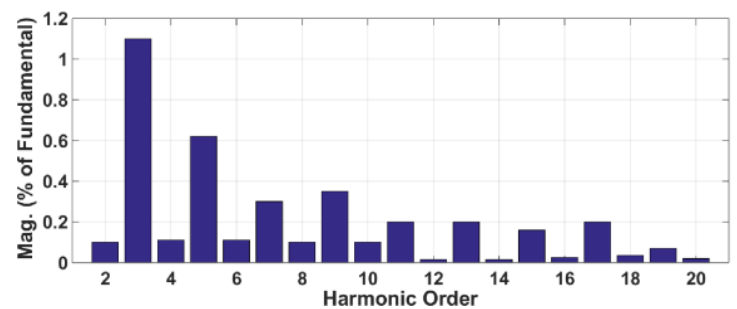

(c)

Fig. 6. Harmonic spectrum of source current simulation results: (a) FLCPID, (b) FLC-PID -SOGA and (c) FLC-PID -MOGA.

\section{CONCLUSION}

As the number of power electronic devices in the power grid grows, so does the content of harmonic current. The impact of harmonic currents on a generator is unavoidable when it is directly linked to the power grid through a step-up transformer. A harmonic elimination approach for induction generators based on a micro hydropower system was developed through research. The applicability of two filtering techniques, passive detuned filtering and active filtering was studied. The objective of this study is to deliver a cost-effective harmonic solution based on a reliable and efficient modular active harmonic filter system based on MOPSO that does not violate IEEE 519-1992 restrictions. The simulations were conducted out utilising a MATLAB/SIMULINK-based test system. The study's findings revealed that by combining detuned and active filters, an improved harmonic removal approach might be developed. Even though it falls short of the IEEE standard of $5 \%$, the hybrid tuned active power filter was able to reduce voltage harmonics from 43 percent to 2.6 percent. The harmonic wave with THD of 67 percent may be reduced to THDi 3 percent using a hybrid tuned active power filter.

\section{REFERENCES}

[1] GM Shafiullah, Tjedza Masola, Remember Samu, Rajvikram Madura Elavarasan, Sharmina Begum, Umashankar Subramaniam, Mohd Fakhizan Romlie, Mohammad Chowdhury, M. T. Arif, "Prospects of Hybrid Renewable Energy-Based Power System: A Case Study, Post Analysis of Chipendeke Micro-Hydro, Zimbabwe", IEEE Access, 2021, Vol. 9.

[2] Jamiu O. Oladigbolu, Makbul A. M. Ramli, Yusuf A. Al-Turki, "Feasibility Study and Comparative Analysis of Hybrid Renewable Power System for off-Grid Rural Electrification in a Typical Remote Village Located in Nigeria", IEEE Access, 2020, Vol. 8.

[3] Irfan Sami, Nasim Ullah, S. M. Muyeen, Kuaanan Techato, Md. Shahariar Chowdhury, Jong-Suk Ro, "Control Methods for Standalone and Grid Connected Micro-Hydro Power Plants with Synthetic Inertia Frequency Support: A Comprehensive Review", IEEE Access, 2020, Vol. 8.

[4] Shivangni Sharma, Vimlesh Verma, "Modified Control Strategy for Shunt Active Power Filter With MRAS-Based DC Voltage Estimation and Load Current Sensor Reduction", IEEE Transactions on Industry Applications, 2021, Vol. 57, Issue 2.

[5] Cheng Gong, Wai-Kit Sou, Chi-Seng Lam, "Design and Analysis of Vector Proportional-Integral Current Controller for LC-Coupling Hybrid Active Power Filter With Minimum DC-Link Voltage", IEEE Transactions on Power Electronics, 2021, Vol. 36, Issue 8.

[6] Siqi Wu, Zhigang Liu, "Low-Frequency Stability Analysis of Vehicle-Grid System with Active Power Filter Based on dq-Frame Impedance", IEEE Transactions on Power Electronics, 2021, Vol. 36, Issue 8 .

[7] Man-Chung Wong, Ying Pang, Zeng Xiang, Lei Wang, Chi-Seng Lam, "Assessment of Active and Hybrid Power Filters Under Space Vector Modulation", IEEE Transactions on Power Electronics, 2021, Vol. 36, Issue 3.

[8] Osman Kukrer, Hasan Komurcugil, Ramon Guzman, Luis Garcia de Vicuna, "A New Control Strategy for Three-Phase Shunt Active Power Filters Based on FIR Prediction", IEEE Transactions on Industrial Electronics, 2021, Vol. 68, Issue 9.

[9] Sabir Ouchen, Mohamed Benbouzid, Frede Blaabjerg, Achour Betka, Heinrich Steinhart, "Direct Power Control of Shunt Active Power Filter Using Space Vector Modulation Based on Supertwisting Sliding Mode Control," IEEE Journal of Emerging and Selected Topics in Power Electronics, 2021, Vol. 9, Issue 3.

[10] Shixi Hou, Yundi Chu, Juntao Fei, "Intelligent Global Sliding Mode Control Using Recurrent Feature Selection Neural Network for Active Power Filter", IEEE Transactions on Industrial Electronics, 2021, Vol. 68, Issue 8.

[11] Gaoxiang Li, An Luo, Zhixing He, Fujun Ma, Yandong Chen, Wenhua Wu, Zhen Zhu, Josep M. Guerrero, “A DC Hybrid Active Power Filter and Its Nonlinear Unified Controller Using Feedback Linearization", IEEE Transactions on Industrial Electronics, 2021, Vol. 68, Issue 7.

[12] Narendra Babu P, Josep M. Guerrero, Pierluigi Siano, Rangababu Peesapati, Gayadhar Panda, "An improved adaptive control strategy 
in grid-tied PV system with active power filter for power quality enhancement", IEEE Systems Journal, 2021, Vol. 15, Issue 2.

[13] Krama A, Zellouma L, Benaissa A, Rabhi B, Bouzidi M, Benkhoris MF, "Design and experimental investigation of predictive direct power control of threephase shunt active filter with space vector modulation using anti-windup PI controller optimized by PSO,' Arabian J Sci Eng, 2019;44:6741-55.

[14] Ouchen S, Betka A, Gaubert J-P, Abdeddaim S., "Simulation and real time implementation of predictive direct power control for three phase shunt active power filter using robust phase-locked loop," Simul Model Pract Theory, 2017;78:1-17.

[15] Aissa O, Moulahoum S, Colak I, Babes B, Kabache N., "Analysis and experimental evaluation of shunt active power filter for power quality improvement based on predictive direct power control, " Environ Sci Pollut Res, 2018;25:24548-60.

[16] Mahaboob S, Ajithan SK, Jayaraman S., "Optimal design of shunt active power filter for power quality enhancement using predator-prey based firefly optimization," Swarm Evol Comput, 2019;44:522-33.

[17] Costa BLG, Graciola CL, Angélico BA, Goedtel A, Castoldi MF. "Metaheuristics optimization applied to PI controllers tuning of a DTC-SVM drive for threephase induction motors," Appl Soft Comput, 2018;62:776-88.

[18] Rameshkumar K, Indragandhi V., "Real time implementation and analysis of enhanced artificial bee colony algorithm optimized PI control algorithm for single phase shunt active power filter," $J$ Electric Eng Technol, 2020.

[19] Long Q., “A constraint handling technique for constrained multiobjective genetic algorithm," Swarm Evol Comput, 2014;15:66-79.

[20] Tian D, Shi Z., "MPSO: Modified particle swarm optimization and its applications," Swarm Evol Comput, 2018;41:49-68

[21] Ismkhan H., "Effective heuristics for ant colony optimization to handle largescale problems," Swarm Evol Comput, 2017;32:140-9.

[22] Akbari R, Hedayatzadeh R, Ziarati K, Hassanizadeh B., "A multiobjective artificial bee colony algorithm," Swarm Evol Comput, 2012;2:39-52.
[23] Babu TS, Priya K, Maheswaran D, Kumar KS, Rajasekar N. "Selective voltage harmonic elimination in PWM inverter using bacterial foraging algorithm," Swarm Evol Comput, 2015;20:74-81.

[24] Parandhaman B, Nataraj SK, Baladhandautham CB., "Optimization of DC-link voltage regulator using Bat algorithm for proportional resonant controllerbased current control of shunt active power filter in distribution network," Int Trans Electrical Energy Syst, 2020;30:e12369.

[25] Awasthi A, Chandra D, Rajasekar S, Singh AK, Karuppanan P., “An Improved PSO approach for optimal tuning of PI controller for shunt active power filter using FPGA with hardware co-simulation", In: 2016 IEEE international conference on power electronics, drives and energy systems (PEDES); 2016, pp. 1-6.

[26] Bharathi SLK, Selvaperumal S., "MGWO-PI controller for enhanced power flow compensation using unified power quality conditioner in wind turbine squirrel cage induction generator," Microprocess Microsyst, 2020:103080.

[27] Mishra AK, Das SR, Ray PK, Mallick RK, Mohanty A, Mishra DK., "PSO-GWO optimized fractional order PID based hybrid shunt active power filter for power quality improvements," IEEE Access, 2020;8:74497-512.

[28] Gali V, Gupta N, Gupta R., "Improved dynamic performance of shunt active power filter using particle swarm optimization," In: 2017 IEEE International Conference on Intelligent Techniques in Control, Optimization and Signal Processing (INCOS); 2017, p. 1-7.

[29] Bengourina MR, Rahli M, Slami S, Hassaine L., "Optimization of direct power control of three-phase shunt active power filter by using PSO algorithm," Synthesis, 2017;101:100.

[30] Sakthivel A, Vijayakumar P, Senthilkumar A, Lakshminarasimman L, Paramasivam S., "Experimental investigations on ant colony optimized PI control algorithm for shunt active power filter to improve power quality control," Eng Pract, 2015;42:153-69.

[31] Thanh HP, Van HD, Duy AN, Duy CN., "Optimizing parameters of the shunt active power filter using Genetic algorithm," In: 2017 9th International Conference on Knowledge and Systems Engineering (KSE). p. 233-8 